\title{
The Public Health Response to the Chi-Chi Earthquake in Taiwan, 1999
}

Kow-Tong Chen, MD, PhD

WEI J. CHEN, MD, SCD

Josephine Malilay, PhD, MPH

Shinng-Jer Twu, MD, PhD ${ }^{d}$

\section{SYNOPSIS}

Objective. On September 21, 1999, at 1:47 a.m., an earthquake measuring 7.3 on the Richter scale struck the middle Chi-Chi region of Taiwan. The present study examines the response of the public health sector to the earthquake.

Methods. A community needs assessment using modified cluster sampling was performed in shelters of Nantou and Taichung Counties five days after the earthquake struck. Twenty-five temporary medical service systems (TMSSs) conducted surveillance for selected diseases and mortality within one week post-earthquake aided by a buddy system that allowed unaffected counties to provide support to affected counties.

Results. The number of cases of acute respiratory infections and acute gastroenteritis in the affected area was higher than that of neighboring unaffected counties in the post-earthquake phase $(p<0.001)$. Earthquake-related deaths were estimated at 2,347 deaths (death rate 116 per 100,000 population); the mean age of the decedents was 49.7 years. No significant difference was observed between males $(120 / 100,000)$ and females $(110 / 100,000)$ (risk ratio $[R R]=1.09 ; 95 \%$ confidence interval $[\mathrm{Cl}] 0.84,1.42 ; p>0.05)$. The age-adjusted mortality rate was significantly higher in 1999 (odds ratio [OR] $=2.11 ; 95 \% \mathrm{Cl}$ $1.99,2.24)$ than in a comparable period in 1998.

Conclusion. Emergency preparedness must be based on carefully conceived priorities, information, and communications, and improved capabilities must be developed to rapidly implement an emergency public health network. The emergency response to this event-consisting of TMSSs, a buddy system, and a communication system-should be considered in planning for future disaster events in Taiwan.

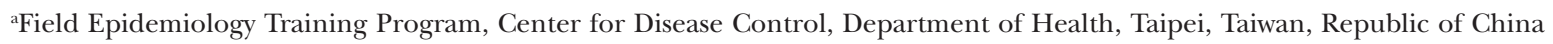

${ }^{b}$ Institute of Epidemiology, College of Public Health, National Taiwan University, Taipei, Taiwan, Republic of China

${ }^{\mathrm{c}}$ National Center for Environmental Health, Centers for Disease Control and Prevention, Atlanta, GA

${ }^{\mathrm{d} C e n t e r}$ for Disease Control, Department of Health, Taipei, Taiwan, Republic of China

Address correspondence to: Shiing-Jer Twu, MD, PhD, Center for Disease Control, Department of Health, No. 6-8F, LinShen South Rd., Taipei, Taiwan, R.O.C; tel. 886-2-2396-7764; fax 886-2-2321-0110; e-mail <ktchen@cdc.gov.tw>. 
Earthquakes have caused more than a million deaths and more than a billion dollars in property loss in the past 20 years worldwide. ${ }^{1,2}$ The magnitude of the earthquake, population density, degree of earthquake disaster preparedness, and mitigation measures are major factors influencing earthquake-related destruction and mortality. ${ }^{1,3}$ The 1999 Chi-Chi earthquake in Taiwan severely challenged the public health system's ability to assess emergency needs and ensure the health and well-being of affected communities. This report describes health issues arising during the emergency response to the earthquake and proposes strategies for response operations after major earthquakes in Taiwan. Further, the lessons learned from the response to this earthquake may help to improve current strategies for preventing casualties and for distributing resources efficiently during response operations.

\section{The Chi-Chi Earthquake}

On September 21, 1999, at 1:47 a.m., an earthquake measuring 7.3 on the Richter scale struck the middle Chi-Chi region of Taiwan, causing widespread destruction. The quake severely affected an estimated 2,025,445 residents in Nantou and Taichung Counties; damaged approximately 92,000 structures $(48,629$ completely destroyed, 43,056 partially destroyed) including homes, businesses, schools, and hospitals and other health care delivery facilities; disrupted utility services; and necessitated major traffic rerouting. ${ }^{4}$ At least 100,000 displaced people went to shelters provided by the government, non-governmental organizations, and schools. Several thousand camped in city parks or erected tents in vacant lots, backyards, or anywhere else deemed safe. As a result, the transportation and communication sectors of both counties were paralyzed.

On September 21, the day of the earthquake, Taiwan's Department of Health initiated a system to respond to potential adverse health effects resulting from the event. A Task Force Committee immediately established medical aid stations to address disruptions in the health care system and immediately delivered tetanus toxoid vaccine to the disaster-stricken areas. Multidisciplinary teams conducted rapid assessments within three days after the earthquake. The Committee also implemented a surveillance system for selected diseases and environmental sanitation within one week post-earthquake and strengthened the public health infrastructure to enhance vaccination services and vector control.

Twenty-five temporary medical service systems (TMSSs), a joint program of the national Department of Health and 17 teaching hospitals, were initiated one week post-earthquake. The TMSSs determined health care needs and services to be provided on a timely basis to the affected people during the postearthquake phase. The TMSSs served more than 90\% of the population living in the affected area. The TMSSs also assessed cases for severity and transferred patients to back-up hospitals, usually unaffected teaching hospitals.

Each TMSS included a disaster surveillance team (DST). Twenty-five disaster surveillance teams (DSTs) made up of staff members from the Field Epidemiology Training Program of the Center for Disease Control, Department of Health, Taiwan, and rotating staff from the county health departments were deployed from September 28 through November 14, 1999, to review medical charts from the 25 TMSSs. In addition to surveillance, the DSTs provided the following services: public health education; referrals for environmental, mental health, and personal health services; counseling services; first aid; monitoring of drinking and wash water sources; garbage disposal; evaluations of fixed and movable latrines; vaccine storage; and monitoring of indices of Aedes aegypti and Aedes albopictus mosquitoes for dengue fever protection.

Continuation of routine public health programs, particularly immunization campaigns, was considered critical despite the disaster event. Because public health workers in the affected areas were exhausted and often unavailable, the Department of Health created a buddy system to allow unaffected counties to provide support to affected counties for two weeks after the quake. Therefore, routine vaccinations continued uninterrupted for all children in the affected areas. People ages 65 years and older were offered free influenza vaccinations. All individuals who prepared food for residents in the disaster zone received free hepatitis $\mathrm{A}$ vaccinations.

\section{METHODS}

\section{Community needs assessment}

A modified rapid community needs assessment using a methodology previously employed after hurricanes ${ }^{5,6}$ was conducted to evaluate the public health needs of the affected areas on September 26. On the basis of maps and population data, shelters in Nantou and Taichung Counties were divided into clusters. In each of the 30 clusters in each county, team representatives interviewed an adult member from each of seven randomly selected households. Respondents were queried about household composition, number of sick and injured household residents, supply of food and water, water purification and access to sanitary toilets, 
access to telephone and electricity, availability of transportation, and need for medical care and medications.

\section{Morbidity and mortality surveillance}

Crude casualty data were obtained from the statistics division of the Ministry of Interior, Taiwan. ${ }^{7}$ Statistical data on deaths and injuries were collected from official reports provided by the Chi-Chi Earthquake Command Post. ${ }^{8}$ We defined earthquake-related injuries as physical injuries sustained during the earthquake of September 21 or its aftershocks, which occurred from September 21 through October 31, 1999. We defined earthquake-related mortality as the rate of deaths resulting from physical injuries sustained during the earthquake or its aftershocks.

We compared disease surveillance data with similar data from the normal sentinel surveillance system, using chi-square tests for categorical variables and $t$-tests for continuous variables.

\section{RESULTS}

\section{Community needs assessment}

On September 26, we surveyed respondents from 420 households (210 from Nantou County and 210 from Taichung County). An average of three people resided in each household (range: one to nine household residents). Of the study households, $5 \%$ in Nantou County and $7 \%$ in Taichung County reported having at least one child younger than 2 years of age, while $18 \%$ of study households in Nantou County and 22\% in Taichung County reported having at least one resident older than 50 years of age. Respondents from $48 \%$ of study households in Nantou County and $46 \%$ in Taichung County stated that an injured person resided in their household. (See Table.)
Almost all households (91\%) reported purification of drinking water, and most (89\%) reported access to public or private transportation. (See Table.) Fewer households reported access to a flushing toilet (40\%), access to a working television set $(24 \%)$, access to electricity $(25 \%)$, access to a telephone $(34 \%)$, and access to garbage collection $(39 \%)$.

\section{Morbidity and mortality surveillance}

During the period from October 4, 1999, through November 14, 1999, 70,718 person-visits were made to the 25 TMSSs. The most commonly reported illnesses were acute respiratory infection ( $50.1 \%$ of visits), musculoskeletal pain $(17.4 \%)$, trauma $(12.5 \%)$, acute gastroenteritis $(7.2 \%)$, and skin rash $(7.1 \%)$. During the first four weeks after the earthquake, cases of acute respiratory infections and acute gastroenteritis identified through normal sentinel surveillance increased in comparison with the number of cases of acute respiratory infections and acute gastroenteritis in nondisaster areas. The incidence of acute respiratory infections and acute gastroenteritis declined to baseline levels four weeks after the earthquake (Figure 1). The incidence of acute respiratory infections and of acute gastroenteritis in affected areas were significantly higher than those in neighboring unaffected counties $(p<0.001)$. We observed 15 cases of shigellosis, a notifiable reporting disease, in Nantou County during the period from September 21, 1999, through October 31, 1999. Four cases had been reported in Nantou County during the comparable period in 1997 and 11 cases during the comparable period in 1998. No outbreak of vaccine-preventable diseases was reported postearthquake in either county.

In all, an estimated 8,700 people sustained injuries following the quake, from September 21, 1999, through

Table. Study households reporting selected conditions after the Chi-Chi earthquake, by county, September 1999

\begin{tabular}{lccc}
\hline Condition & $\begin{array}{c}\text { Nantou County } \\
\text { percent } \\
(\mathrm{n}=210)\end{array}$ & $\begin{array}{c}\text { Taichung County } \\
\text { percent } \\
(\mathrm{n}=210)\end{array}$ & $\begin{array}{c}\text { Total percent } \\
(\mathrm{n}=420)\end{array}$ \\
\hline Injured person in household & 48 & 46 & 47 \\
Purification of drinking water & 90 & 92 & 91 \\
Access to a flushing toilet & 37 & 43 & 40 \\
Access to a working television set & 21 & 27 & 24 \\
Access to electricity & 22 & 28 & 25 \\
Access to a telephone & 24 & 43 & 34 \\
Access to garbage collection & 33 & 45 & 39 \\
Access to public or private transportation & 88 & 90 & 89 \\
\hline
\end{tabular}


Figure 1. Crude incidence of acute respiratory infections and acute gastroenteritis in disaster and non-disaster areas after the Chi-Chi earthquake, Taiwan, September 21, 1999

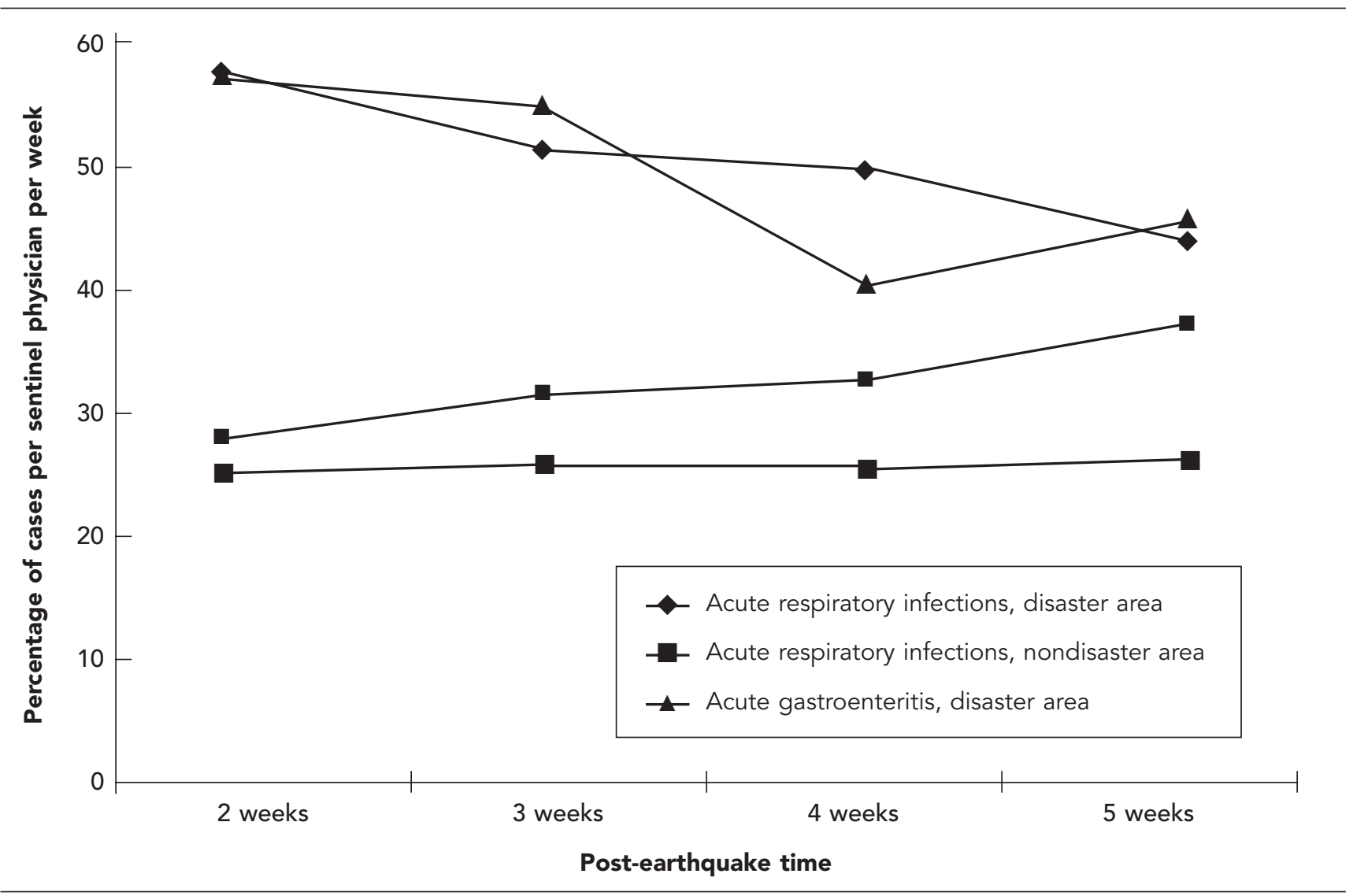

October 31, 1999. An estimated $90 \%$ of injured patients sustained head injuries, open wounds, or fractures. A total of 2,347 deaths were reported in the two counties during the same time period (death rate of 116 per 100,000 population). The average age of decedents was 49.7 years (males 50.7 years; females 49.0 years). Compared with a comparable period in 1998, the age-adjusted mortality rate was significantly higher in 1999 (410 per 100,000 population vs. 183 per 100,000 population; $\mathrm{RR}=2.11 ; 95 \%$ CI $1.99,2.24 ; p<0.0001$ ). Age-specific death rates ranged from 44 per 100,000 for the 20-24 age group to 340 per 100,000 for those older than 75 years of age. The age-specific death rate increased steadily among those older than 55 years, but with almost identical rates for males (120 per $100,000)$ and females (110 per 100,000) (RR=1.09; $95 \%$ CI $0.84,1.42 ; p>0.05$ ) (Figure 2). The most frequent causes of death were injuries to the vital organs $(56.2 \%)$ and suffocation $(31 \%)$.

An estimated 50,292 (35\%) people ages 65 years or older received influenza vaccinations from September 21 through October 31, and 3,750 food handlers in affected areas received hepatitis A vaccinations.

\section{Emergency response}

Immediately after the earthquake, most essential utilities were disrupted. First responders became physically exhausted in the affected areas, highlighting the importance of buddy systems for back-up and mutual support. An emergency plan consisting of a buddy system was initiated two weeks post-earthquake to allow neighboring counties to provide support to the affected counties. This arrangement allowed routine preventive measures for infectious diseases, such as vaccinations, to continue without interruption.

In the rural areas, where outdoor pipes provided the main source of water in nondisaster times, the system's damaged state rendered water supplies unsafe without boiling or treatment. However, although bottled water was supplied, outdoor pipes continued 
Figure 2. Earthquake-related age-specific death rates, Taiwan, 1999

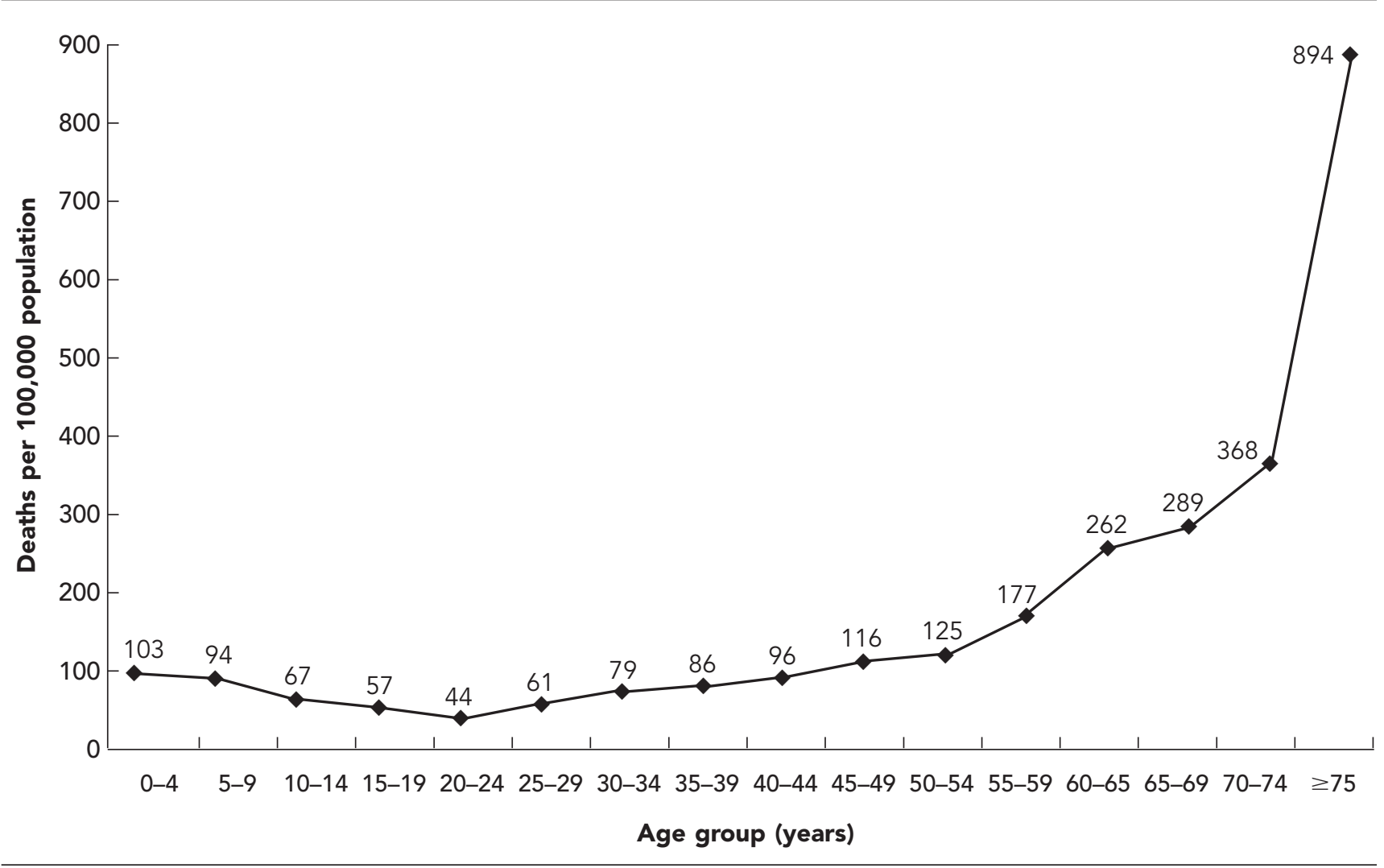

to be favored by affected communities. This event indicated that outdoor pipes should be tagged or covered to prevent their use until proper repair can be made. Other environmental issues included inadequate toilet and handwashing facilities and inadequate trash disposal. Food handling and storage were inadequate because of the lack of refrigeration and handwashing facilities, and might have contributed to an increased incidence of acute gastroenteritis in affected areas.

The DSTs and volunteer agencies addressed these deficiencies and obtained appropriate resources, such as additional handwashing facilities. They further assisted in safeguarding public health by mobilizing and using community and other agency resources for environmental health interventions, child protective services, mental health, personal sanitation and hygiene, food, shelter, and transportation. The teams also aided in correcting public safety concerns such as unsafe lighting, unsanitary toilets, and exposure to cold and rain. For example, when some teams found candles used for lighting in tent-enclosed spaces and toilets constructed over water sources, they recommended measures to safeguard against potential injury and illness.

The DSTs also assisted in reducing adverse health effects by implementing evacuation procedures, community education, injury management, rapid community assessment, and improvements in water supply and sanitation, and by establishing a simple, flexible, timely surveillance system.

Because the communication base of the island was destroyed, normal communications networks including wire and wireless phones were nonfunctional. This resulted in independent operations of the fire department, police force, and ambulances. Limited communications further affected other critical areas of response. For instance, triage systems could have been organized by the local Disaster Prevention and Response Department and standardized for emergency medicine specialists so that precious time could have been used to save lives. Massive quantities of donated goods (e.g., 70 tons of rice, six million vitamin tablets, 35,000 cans of milk powder, 500,000 bottles of water) from other counties throughout the island were deliv- 
ered without coordination to affected areas and resulted in the paralysis of thoroughfares into the disaster zone.

As in the earthquake in Kobe, Japan, ${ }^{9}$ normal communications networks could not be relied upon in this emergency situation. Satellite communications were considered as an alternative for contacts between administrative agencies and among major medical centers and the disaster prevention and response center. As part of disaster planning, neighboring cities should set up links that can be maintained if a city's communication base is destroyed completely. In this manner, communications can be maintained at all times between the disaster site and areas that can offer external assistance.

\section{DISCUSSION}

Mortality associated with the Chi-Chi earthquake (116 per 100,000 population) was higher than that for an earthquake of similar magnitude in California (3.4 per 100,000 population). ${ }^{10}$ Construction techniques, damage to dwellings, physical disabilities, and inadequate resuscitation may have been risk factors for death after the earthquake in California. ${ }^{11,12}$ However, evaluation of risk factors for death after the Chi-Chi earthquake was not undertaken during emergency response.

Valid information is critical to enable decision-making and resource prioritization by health care providers and emergency management officials during the response immediately after a disaster. ${ }^{13,14}$ Rapid assessment of health needs in populations affected by disasters is an important first step in guiding relief efforts. ${ }^{15}$ The survey during this earthquake provided some of the earliest objective data describing the status of the affected population after the disaster. For example, on the basis of survey findings, officials of the Center for Disease Control decided not to provide bottled water in selected urban areas because a high proportion of the affected population had access to purified water. In addition, based on the surveillance data, ${ }^{16}$ expensive interventions (e.g., mass aerial spraying for disease vectors and nuisance insects) were determined to be unnecessary by the Center for Disease Control, Taiwan. One case of dengue fever was detected in the middle region of Taiwan, in contrast to a baseline level indicating that more than $90 \%$ of cases of this illness occur in the southern part of the island. ${ }^{16}$ Environmental sanitation interventions were performed only in areas where DSTs reported a need.

Previous studies have suggested that natural disasters do not import diseases that are not already present in affected areas. Furthermore, outbreaks of personto-person diseases do not occur after earthquakes. ${ }^{17,18}$ However, major disasters can be followed by an increase in incidence and outbreaks of infectious diseases, ${ }^{19,20}$ and a strong link exits between the extent of damage caused by catastrophic earthquakes and an increase in morbidity rates for acute illness. ${ }^{21}$ Usual post-disaster sanitation measures combined with the strengthening of disease surveillance systems are generally sufficient for controlling transmission of epidemic diseases..$^{18}$ In this earthquake, the incidences of acute respiratory infections and diarrheal diseases were higher than those of the unaffected area in the first four weeks, but no outbreaks were reported. The increased incidence of acute respiratory infections and diarrheal diseases could be attributed to seasonal variation and crowded conditions.

Historically, infectious disease epidemics have accounted for deaths in the aftermath of an earthquake. With population increases and rapid urbanization in earthquake-risk zones, earthquakes resulting in high mortality and morbidity are expected to occur in the future. In this earthquake, an emergency plan consisting of a buddy system, TMSSs, and a communication system for disasters was helpful for establishing strategies to reduce morbidity and mortality in future events.

The authors thank the staff of the Center for Disease Control, Department of Health, Taiwan; the County Bureaus of Health, Taiwan; and the Field Epidemiology Training Program for their help in the post-earthquake management and investigation.

\section{REFERENCES}

1. Noji EK. Earthquake. In Noji EK, editor. The public health consequences of disasters. New York: Oxford University Press; 1997. p. 135-78.

2. Tanaka H, Oda J, Iwai A, Kuwagata Y, Matsuoka T, Takaoka M, et al. Morbidity and mortality of hospitalized patients after the 1995 Hanshin-Awaji earthquake. Am J Emerg Med 1999;17:186-91.

3. Toole MJ. Communicable disease epidemiology following disasters. Ann Emerg Med 1992;214:418-20.

4. Department of Health, Republic of China. Deaths in 9/21 earthquake, 1999. Taipei: Department of Health; 2000.

5. Rapid health needs assessment following Hurricane Andrew-Florida and Louisiana, 1992. MMWR Morb Mortal Wkly Rep 1992;41:685-8.

6. Malilay J, Flanders WD, Brogan D. A modified clustersampling method for post-disaster rapid assessment of needs. Bull World Health Organ 1996;22:1715-20.

7. Ministry of Interior, Republic of China [cited 2003 Mar 10]. Available from: URL: http://www.ris.gov.tw/ch4 /static/year/list.htm 
8. National Fire Department Administrations, Ministry of Interior, Republic of China [cited 2003 Mar 10]. Available from: URL: http://www.nfa.gov.tw/acdept/h0934 .htm

9. Shigeaki B, Hiroshi T, Seiki N, Shuhei T, Kenzo I, Shuichi O. The great Hanshin earthquake. Lancet 1996; 347:307-9.

10. Earthquake-associated deaths-California. MMWR Morb Mortal Wkly Rep 1989;38:767-70.

11. Osaki Y, Minowa M. Factors associated with earthquake deaths in the great Hanshin-Awaji earthquake, 1995. Am J Epidemiol 2001;153:153-6.

12. Yi-Szu W, Chung-Ping H, Tzu-Cheh L, Dar-Yu Y, TainCheng W. Chest injuries transferred to trauma centers after earthquake, 1999, Taiwan. Am J Emerg Med 2000; 18:825-7.

13. Wagner RM, Jones NP, Smith GS. Risk factors for casualty in earthquakes: the application of epidemiologic principles to structural engineering. Structural Safety 1994;13:177-200.

14. de Ville de Goyet C, del Cid E, Romero A, Jeannee E, Lechat M. Earthquake in Guatemala: epidemiologic evaluation of the relief effort. Bull Pan Am Health Organ 1976;10:95-109.
15. Lillibridge S, Niji E, Burkle F. Disaster assessment: the emergency health evaluation of a population affected by a disaster. Ann Emerg Med 1993;22:1715-20.

16. Department of Health, Taiwan. Statistics of communicable diseases and surveillance report in Taiwan area, 1988-2000. Taipei: Department of Health; 2001.

17. Spencer HC, Campbell CC, Romero A, Zeissig O, Feldman RA, Boostrom ER, Long EC. Disease surveillance and decision-making after the 1976 Guatemala earthquake. Lancet 1977;2(8030):181-4.

18. World Health Organization. Public health consequences of earthquakes. Geneva: WHO; 1999.

19. Aghababian RV, Teuscher J. Infectious diseases following major disasters. Ann Emerg Med 1992;21:362-7.

20. Schneider E, Hajjeh RA, Spiegel RA, Jibson RW, Harp EL, Marshall GA, et al. A coccidioidomycosis outbreak following the Northridge, Calif, earthquake. JAMA 1997;277:904-8.

21. Matsuoka T, Yoshioka T, Oda J, Tanaka H, Kuwagata Y, Sugimoto H, Sugimoto T. The impact of a catastrophic earthquake on morbidity rates for various illnesses. Public Health 2000;114:249-53. 